\title{
CROMATOGRAFIA NEGATIVA EM AMINOHEXIL- AGAROSE: SEPARAÇÃO DE FRAGMENTOS Fab HUMANO
}

\author{
G. P. CARMIGNOTTO ${ }^{1}$ e S. M. A. BUENO ${ }^{1}$ \\ ${ }^{1}$ Universidade Estadual de Campinas, Faculdade de Engenharia Química \\ E- mail para contato: bi.gabrielapc@gmail.com
}

\begin{abstract}
RESUMO - Os fragmentos de imunoglobulina $\mathrm{G}$ são moléculas empregadas em testes diagnósticos e terapias. Usualmente são purificados por cromatografia de afinidade em proteínas $\mathrm{A}$ ou $\mathrm{G}$ imobilizadas em matrizes sólidas. No entanto, esses ligantes apresentam algumas desvantagens, sendo a principal delas o alto custo. Como ligantes alternativos de baixo custo, têm sido propostos o emprego de diaminas imobilizadas. Neste trabalho foi avaliada a separação de fragmento Fab humano por cromatografia negativa (proteína alvo obtida na fração nãoretida) em aminohexil-agarose, em diferentes sistemas tamponantes, na faixa de $\mathrm{pH}$ 6,0 a 8,5. A seletividade do adsorvente foi avaliada por eletroforese SDSPAGE e Western blot. Os resultados mostraram que a adsorção de proteínas na coluna ocorre entre os valores de $\mathrm{pH}$ de 7,0 a 8,5, tendo obtido fragmentos Fab separados dos fragmentos Fc na fração não-retida em tampão Tris-HCl pH 8,5.
\end{abstract}

\section{INTRODUÇÃO}

Os fragmentos Fab de imunoglobulinas $\mathrm{G}$ ( $\mathrm{IgG}$ ) vêm sendo empregados em diagnósticos e aplicações terapêuticas. Por apresentarem tamanho reduzido, o uso dos fragmentos em algumas aplicações é preferível em relação à IgG intacta, pois possibilitam maior poder de penetração e maior velocidade de circulação. Além disso, o uso desses fragmentos previne possíveis reações adversas relativas à função efetora da porção Fc da imunoglobulina (Yu e Ghosh, 2009; Roque et al., 2005; Rothlinberger et al., 2005; Ljunglof et al., 2007; Elbakri et al., 2010; Hollister e Hudson, 2005). Os fragmentos Fab são obtidos a partir da clivagem enzimática da IgG pela papaína ou por tecnologia do DNA recombinante (Hollister e Hudson, 2005; Cheung et al., 2003).

A purificação dos fragmentos Fab é realizada principalmente por técnicas de cromatografia de afinidade em proteína A ou proteína $\mathrm{G}$ imobilizadas. Entretanto, esses ligantes possuem alto custo e podem sofrer degradação ou ocorrer seu desprendimento da matriz cromatográfica, resultando em contaminação do produto. Como alternativa a esses ligantes têm sido propostos ligantes de menor custo e que apresentem alta estabilidade, 
capacidade, simplicidade e seletividade (Bresolin et al., 2009; Ljunglof et al., 2007; Roque et al., 2005; Willems et al., 2003).

Como uma alternativa, neste trabalho é proposto como ligante a diamina aminohexil imobilizada em agarose para a purificação de fragmentos Fab por cromatografia negativa. A cromatografia negativa consiste na recuperação do produto nas frações não retidas da cromatografia, sendo retidas no adsorvente as impurezas (Bresolin et al., 2009).

Devido a sua estrutura, as diaminas apresentam carga positiva em ampla faixa de valores de $\mathrm{pH}$, possibilitando a interação eletrostática com moléculas negativas. No entanto, dependendo do tamanho de sua cadeia carbônica e do braço espaçador utilizado, as interações hidrofóbicas entre a molécula alvo e o ligante não podem ser excluídas (Houen et al., 2001; Souza et al., 2010).

Neste trabalho foi avaliada a separação de fragmento Fab humano por cromatografia negativa em aminohexil (1,6 diaminohexano)-agarose (epóxi-ativada), em diferentes sistemas tamponantes, na faixa de valores de $\mathrm{pH}$ 6,0 a 8,5. A seletividade do adsorvente foi avaliada por eletroforese SDS-PAGE e Western blot.

\section{MATERIAIS E MÉTODOS}

\subsection{Materiais}

O gel $\omega$-aminohexil-Sepharose 4B ("epoxy activated") foi adquirido da Sigma-Aldrich (EUA). A IgG humana foi adquirido da CSL Behring (Alemanha). Anticorpo de cabra antiFab específico conjugado com peroxidase, anticorpo de cabra anti-Fc específico conjugado com peroxidase, a papaína, a L-cisteína, a iodoacetamida, o Comassie brilliant blue R-250, o Hepes (ácido 2-[4-(2-hidroxietil) 1-piperazinil]-etanosulfônico), o Bis-Tris e o Tris (hidroximetil) amino metano foram obtidos da Sigma-Aldrich (EUA). O fosfato de sódio monobásico e dibásico foram obtidos da Merck (Alemanha). Marcador de baixa massa molar para eletroforese, membrana de nitrocelulose e marcador de massa molar pré-corado para Western blot foram adquiridos da GE Healthcare (EUA). Os demais reagentes utilizados foram todos de grau analítico. Utilizou-se água ultrapura Milli-Q (Millipore, EUA) para preparação de todas as soluções.

\subsection{Métodos}

Obtenção dos fragmentos Fab: Os fragmentos Fab e Fc foram obtidos pela clivagem enzimática da IgG humana pela ação da papaína, de acordo com Ternynck e Avrameas, (1987). Após a fragmentação, a solução tampão da amostra contendo os fragmentos foi 
trocada em coluna PD-10 Sephadex G 25, de acordo com protocolo fornecido pela GE Healthcare (EUA).

Experimentos cromatográficos: Os experimentos foram realizados em sistema de cromatografia de fase líquida de baixa pressão (Bio-Rad, EUA), em temperatura ambiente, na vazão de $0,5 \mathrm{~mL} \mathrm{~min}^{-1}$, em duplicatas. $\mathrm{O}$ volume do leito ( $\omega$-aminohexil-agarose) foi de 1,5 $\mathrm{mL}$ (colunas de $1 \mathrm{~cm}$ de diâmetro por $10 \mathrm{~cm}$ de altura, GE Healthcare, EUA). A coluna foi equilibrada com tampão de adsorção (tampões Tris-HCl, Hepes, fosfato de sódio e Bis-Tris, todos a $25 \mathrm{mmol} \mathrm{L}^{-1}$, na faixa de $\mathrm{pH}$ de 6,0 a 8,5). A coluna foi alimentada com 1,0 mL de solução de fragmentos de $\operatorname{IgG}$ clivada, na concentração de $3,5 \mathrm{mg} \mathrm{mL}^{-1}$. A eluição foi conduzida com o tampão de adsorção contendo $1,0 \mathrm{~mol} \mathrm{~L}^{-1}$ de $\mathrm{NaCl}$ e a regeneração com solução de $\mathrm{NaOH} 25 \mathrm{mmol} \mathrm{L}{ }^{-1}$. Durante toda a cromatografia, frações de $1,0 \mathrm{~mL}$ foram coletadas da corrente de saída.

Métodos analíticos: A dosagem de proteínas totais foi realizada de acordo com método proposto por Bradford (1976). A seletividade do adsorvente foi analisada por eletroforese em gel de poliacrilamida a $10 \%$, sob condições não redutoras (SDS-PAGE), utilizando-se as frações cromatográficas com maior concentração de fragmentos. O teste imunoenzimático Western blot foi utilizado para identificar os fragmentos presentes nas frações de maior concentração (Towbin et al., 1979).

\section{RESULTADOS E DISCUSSÕES}

A separação dos fragmentos Fab em $\omega$-aminohexil-Sepharose foi avaliada quanto a recuperação seletiva dos fragmentos $\mathrm{Fab}$ a partir da solução de clivagem enzimática de IgG humana. Os ensaios cromatográficos foram realizados em tampões Hepes, Tris- $\mathrm{HCl}$, fosfato de sódio e Bis-Tris, em valores de $\mathrm{pH}$ na faixa de 6,0 a 8,5, de acordo com a faixa tamponante de cada tampão. Como os fragmentos Fc possuem pI de 5,5 a 6,7, e os fragmentos Fab, pI de 6,0 a 9,3, espera-se que na faixa de $\mathrm{pH}$ utilizado, a maior proporção dos fragmentos $\mathrm{Fc}$ apresente carga líquida negativa, sendo adsorvidos por meio de interações eletrostáticas com o grupamento amino primário do aminohexil, enquanto os fragmentos Fab sejam recuperados nas frações não retidas. (Mourão, 2014).

Observa-se maior adsorção de proteínas no adsorvente na faixa de valores de $\mathrm{pH}$ 7,0 a 8,5 (Figura 1). O efeito do $\mathrm{pH}$ das soluções tamponantes na capacidade de adsorção das impurezas está relacionada à interação de cargas entre proteínas, o gel e o tampão e os efeitos hidrofóbicos. 


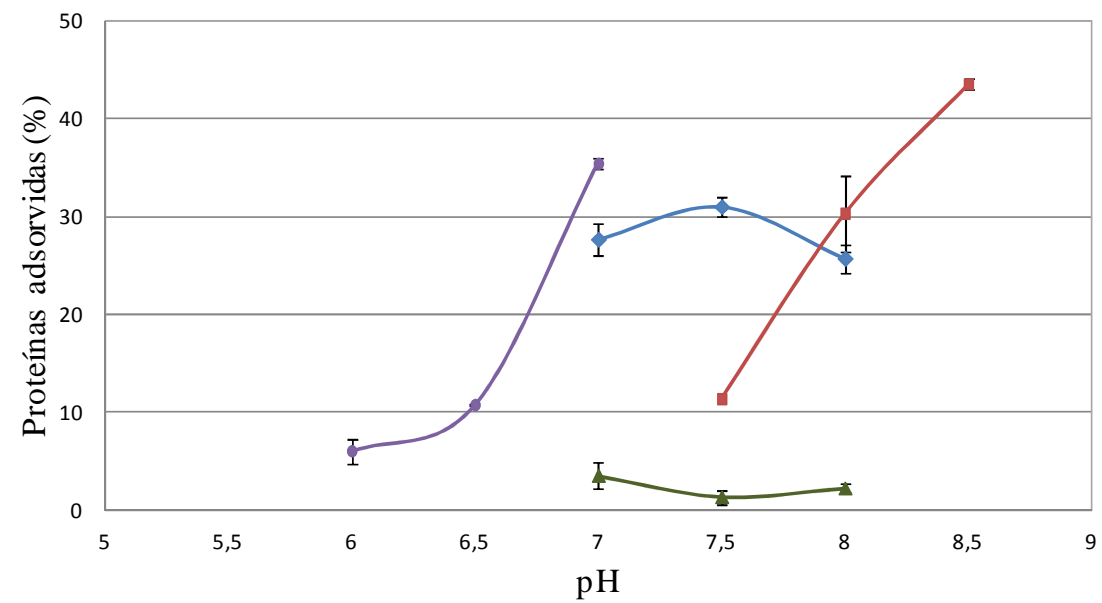

Figura 1- Efeito do $\mathrm{pH}$ e dos sistemas tamponantes Hepes $(\rightarrow)$, Tris- $\mathrm{HCl}(\rightarrow-)$, fosfato de sódio $(-)$ e Bis-Tris $(\rightarrow)$ na adsorção de proteínas totais em $\omega$-aminohexil-Sepharose.

As Figuras 2, 3 e 4 indicam o perfil eletroforético e Western blot dos experimentos que apresentaram maior porcentagem de proteínas totais adsorvidas (Hepes a pH 7,0, 7,5 e 8,0, Tris-HCl a pH 8,0 e 8,5, e Bis-Tris a pH 7,0).
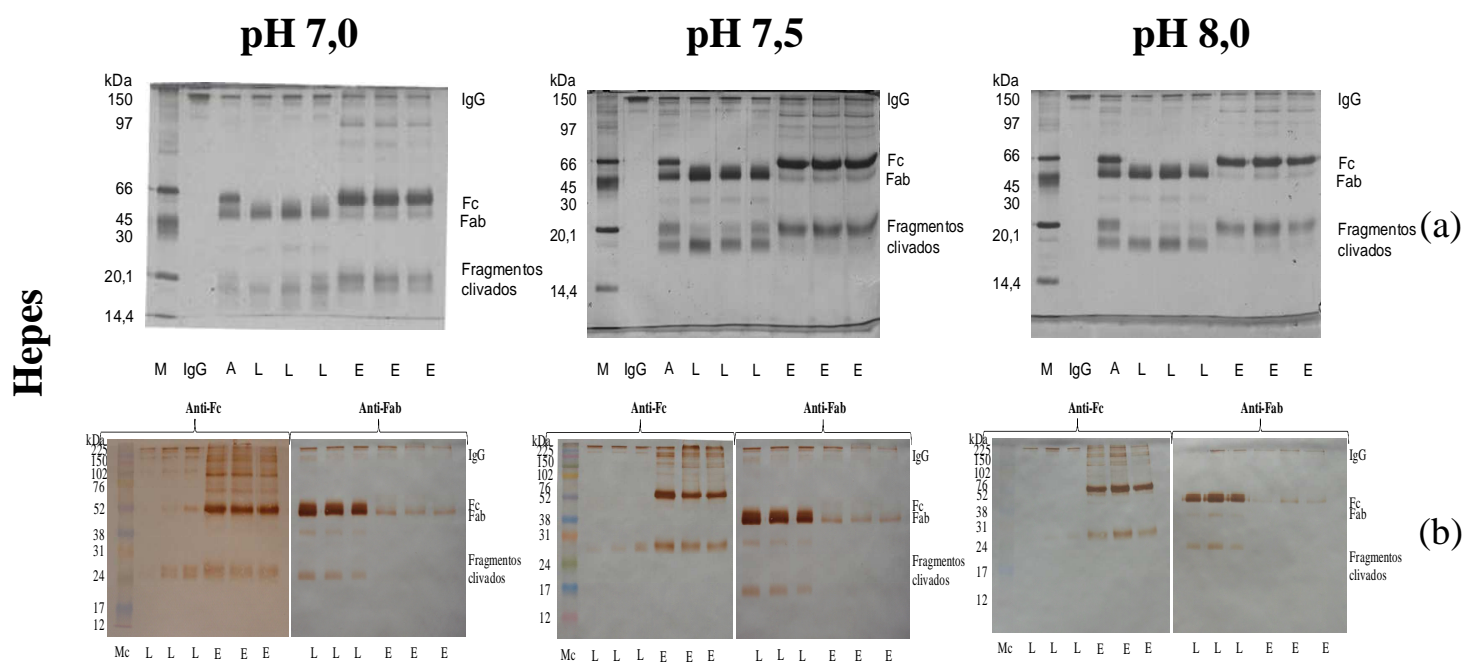

Figura 2- Perfil eletroforético e Western blot da separação de fragmentos Fab de IgG humana em $\omega$-aminohexil-Sepharose em Hepes. (a) Perfil eletroforético. M: Marcador de baixa massa molecular. IgG: Marcador de IgG. A: Amostra de injeção. L: Frações de lavagem. E: Frações de eluição. (b) Western blot: Mc: Marcador pré-corado. L: Frações de lavagem. E: Frações de eluição. 

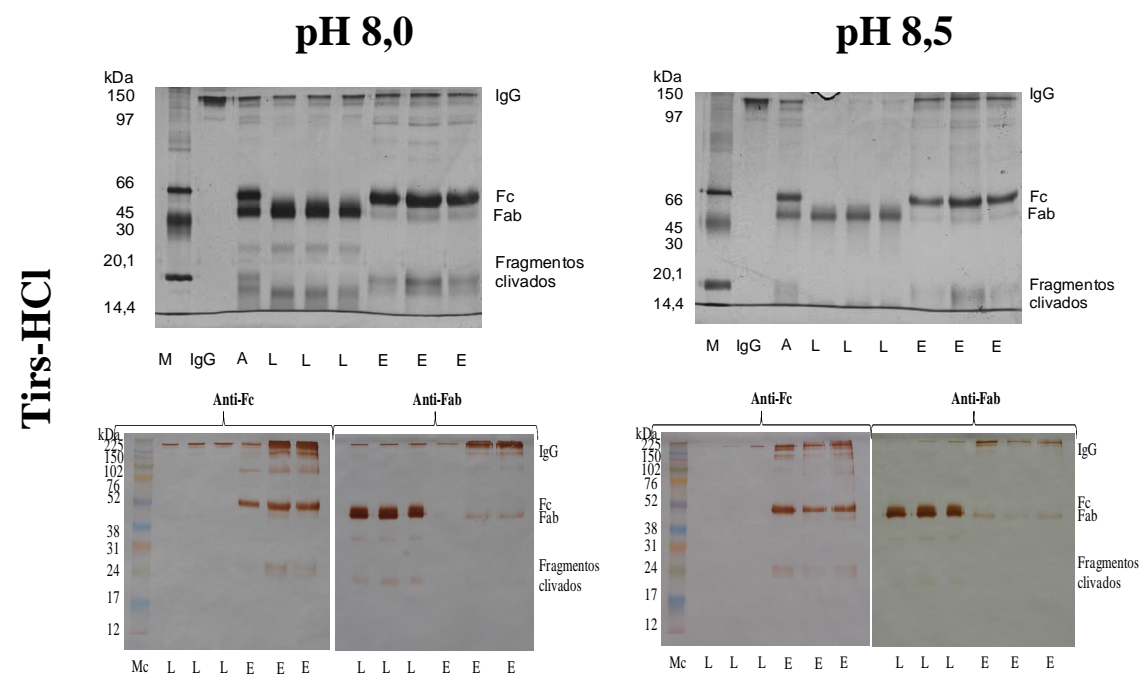

(a)

(b)

Figura 3- Perfil eletroforético e Western blot da separação de fragmentos Fab de IgG humana em $\omega$-aminohexil-Sepharose em Tris-HCl. (a) Perfil eletroforético. M: Marcador de baixa massa molecular. IgG: Marcador de IgG. A: Amostra de injeção. L: Frações de lavagem. E: Frações de eluição. (b) Western blot: Mc: Marcador pré-corado. L: Frações de lavagem. E: Frações de eluição.

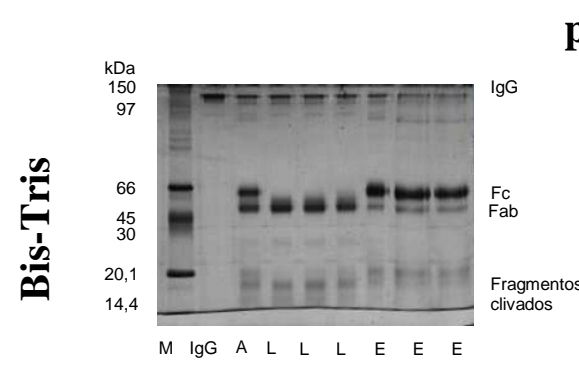

(a)

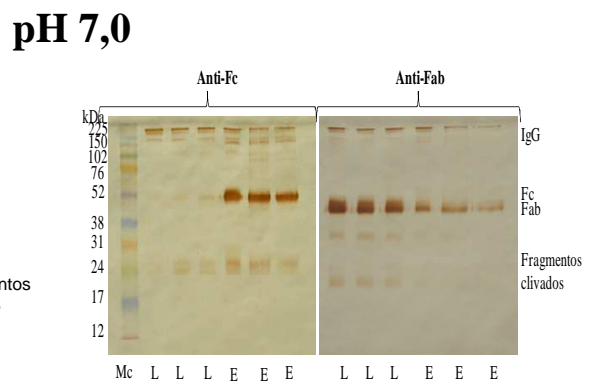

(b)

Figura 4- Perfil eletroforético e Western blot da separação de fragmentos Fab de IgG humana em $\omega$-aminohexil-Sepharose em Bis-Tris. (a) Perfil eletroforético. M: Marcador de baixa massa molecular. IgG: Marcador de IgG. A: Amostra de injeção. L: Frações de lavagem. E: Frações de eluição. (b) Western blot: Mc: Marcador pré-corado. L: Frações de lavagem. E: Frações de eluição.

A recuperação seletiva dos fragmentos $\mathrm{Fab}$ nas frações não retidas foram observadas nos tampões Hepes a pH 7,5 e 8,0, e Tris- $\mathrm{HCl}$ a pH 8,0 e 8,5.

O tampão Tris- $\mathrm{HCl}$ apresenta carga positiva em $\mathrm{pH}$ abaixo de seu $\mathrm{pKa}$, e não apresenta carga em pH acima de seu pKa. Em pH 8,5, o tampão apresenta-se sem carga, não 
interferindo na adsorção dos fragmentos Fc. Em pH 7,5, o tampão carregado positivamente pode interagir com os fragmentos Fc negativamente carregados, mascarando os sítios dos fragmentos que seriam adsorvidos na coluna.

Os resultados para o tampão Bis-Tris mostraram que a separação não foi possível na faixa tamponante deste tampão. Embora o tampão Bis-Tris tenha comportamento semelhante ao tampão Tris- $\mathrm{HCl}$ quanto à carga, sendo positivo abaixo de seu pKa e neutro acima, o valor de $\mathrm{pH}$ 7,0 (acima do pKa do Bis-Tris) é próximo ao valor do pI dos fragmentos Fc, podendo haver fragmentos que não estejam negativos, sendo recolhidos nas frações de lavagem.

O tampão fosfato de sódio não favoreceu a adsorção das proteínas na coluna. O fosfato de sódio possui pKa muito baixo, apresentando carga negativa em sua estrutura nos valores de pH utilizados nas cromatografias. É possível que o ânion fosfato interaja com o aminohexil, dificultando a adsorção dos fragmentos Fc.

O tampão Hepes é um tampão zwiteriônico, apresentando duas cargas de sinais opostos em valores de $\mathrm{pH}$ abaixo de seu pKa. Assim, em pH 7,0 e 7,5, o Hepes não promove nem impede a adsorção dos fragmentos $\mathrm{Fc}$. Em valores de $\mathrm{pH}$ maiores que seu pKa, o tampão apresenta-se carregado negativamente. Essa carga faz com que o tampão interaja com o adsorvente, diminuindo a capacidade de adsorção e aumentando a seletividade (Figuras 1 e 2, respectivamente). Foi possível separar os fragmentos Fab em tampão Hepes, quando carregado negativamente, pois provavelmente o grupamento $\mathrm{SO}_{3}{ }^{-}$presente em sua estrutura não apresente grande afinidade com o adsorvente, contrário ao que ocorre com o ânion fosfato.

A separação dos fragmentos Fab foi possível, em algumas condições, devido principalmente às interações eletrostáticas entre os fragmentos $\mathrm{Fc}$ carregados negativamente em pHs maiores que seus pontos isoelétricos e a matriz carregada positivamente, além das interações presentes entre os tampões estudados e o adsorvente e as proteínas. Em Tris- $\mathrm{HCl}$ a pH 8,5 obteve-se ausência de bandas de fragmentos Fc e com fracas bandas de IgG intacta nas frações não retidas, além de alta capacidade de adsorção da coluna.

\section{CONCLUSÃO}

O uso da diamina aminohexil imobilizada em agarose (epóxi-ativada), possibilitou a separação dos fragmentos Fab dos fragmentos Fc e IgG humana não clivada. A condição com maior grau de pureza nas frações não retidas foi tampão Tris- $\mathrm{HCl} 25 \mathrm{mmol} \mathrm{L}^{-1} \mathrm{pH} 8,5$. 


\section{REFERÊNCIAS}

BRADFORD, M. M. A rapid and sensitive method for the quantitation of microgram quantities of protein utilizing the principle of protein-dye binding. Anal. Biochem., v. 72, p. 248-254, 1976.

BRESOLIN, I.T.L.; BORSOI-RIBEIRO, M.; CARO, J.R.; dos SANTOS, F.P.; CASTRO, M.P.; BUENO, S.M.A. Adsorption of human serum proteins onto TREN-agarose: purification of human IgG by negative chromatography. J. Chromatogr. B, v. 877, p. 17-23, 2009.

CHEUNG, G.L.M; THOMAS, T.M.; RYLATT, D.B. Purification of antibody Fab and $\mathrm{F}(\mathrm{ab})_{2}$ fragments using Gradiflow technology. Protein Expres. Purif., v. 32, p. 135$140,2003$.

ELBAKRI, A.; NELSON, P.N.; ODEH, R.O.A. The state of antibody therapy. Hum. Immunol., v. 71, p. 1243-1250, 2010.

HOLLIGER, P.; HUDSON, P.J. Engineered antibody fragments and the rise for single domains. Nat. Biotechnol., v. 23, p. 1126-1136, 2005.

HOUEN, G. Aminoalkyl affinity matrices. J. Biochem. Biophys. Methods, v. 49, p. 189-197, 2001.

LJUNGLÖF, A.; LACKI, K.M.; MUELLER, J.; HARINARAYAN, C.; van REIS, R.; FAHENER, R.; ALSTINE, J.M.V. Ion exchange chromatography of antibody fragments. Biotechnol. Bioeng., v. 96, no. 3, 2007.

MOURÃO, Cecília Alves. Purificação de fragmentos Fab humano em níquel, cobre, cobalto e zinco quelatados ao CM-Asp. 100 f. (Dissertação de mestrado) - Faculdade de Engenharia Química, Universidade Estadual de Campinas, a ser defendida em 29/05/2014.

ROQUE, A.C.A.; TAIPA, M.A.; LOWE, C.R. An artificial protein L for the purification of immunoglobulins and Fab fragments by affinity chromatography. J. Chromatogr. A, v. 1064, p. 157-167, 2005.

RÖTHLISBERGER, D.; HONNEGGER, A.; PLUNCKTHUN, A. Domain interactions in the Fab fragment: a comparative evaluation of the single-chain Fv and Fab format engineered with variable domains of different stability. J. Mol. Biol., v. 347, p. 773-789, 2005 .

SOUZA, M.C.M.; BRESOLIN, I.T.L.; BUENO, S.M.A. Purification of human IgG by negative chromatography on $\omega$-aminohexyl-agarose. J. Chromatogr. B, v. 878, p. 557$566,2010$. 
TERNYNCK, T.; AVRAMEAS, S. Techniques immune-enzymatiques. Techniques en immunologie. Editora Les Editions Inserm, Societé Française d'Immunologie, 1987.

TOWBIN, H.; STAEHELI, T.; GORDON, J. Electrophorectic transfer of proteins form polyacrylamide gels to nitrocellulose sheets: Procedure and some applications. Proc. Natl. Acad. Sci. USA, v. 76, p. 4350-4354, 1979.

WILLEMS, A.; LEOEN, J.; SCHOONOOGHE, S.; GROOTEN, J.; MERTENS, N. Optimizing expression and purification from cell culture medium of trispecific recombinant antibody derivatives. J. Chromatogr. B, v. 786, p. 161-176, 2003.

YU, D.; GHOSH, R. Integrated fragmentation of human IgG and purification of Fab using a reactant adsorptive membrane bioreactor separator system. Biotechnol. Bioeng., v. 104, no. $1,2009$. 